\title{
Los recorridos de San Pedro y Santiago Apóstol: UN ELEMENTO CENTRAL EN LA RECREACIÓN DE LA TERRITORIALIDAD NAHUA-POPOLUCA
}

\section{Saint Pedro and Apostle Santiago's Regional Trips as Means to Recreate Popoluca's TERRITORIALITY}

\section{Emilia Velázquez H. ${ }^{1}$}

Resumen: En este artículo se explica cómo dos grupos indígenas que habitan en dos municipios del sur de Veracruz y hablan diferentes lenguas —nahuas de Mecayapan y zoque-popolucas de Soteapan-construyeron un territorio compartido cuyo eje central fue el uso mancomunado de las tierras a lo largo de varios siglos. También se analizan los efectos que la reforma agraria tuvo en la desestructuración parcial de este territorio, marcando fronteras internas inexistentes hasta entonces. Se muestra, a la vez, cómo dos prácticas culturales - las visitas de los santos y las velaciones - han posibilitado la recreación simbólica del antiguo territorio nahua-popoluca pese a haber desaparecido el uso mancomunado de las tierras entre Mecayapan y Soteapan. El análisis se centra en los desfases y tensiones existentes entre, por un lado, las prácticas locales de apropiación del espacio y, por otra parte, las legislaciones y disposiciones administrativas del Estado. También se reflexiona sobre el papel que ciertas prácticas culturales - en este caso de origen religioso - tienen en la conformación de territorialidades que recrean territorios ya fragmentados.

${ }^{1}$ Doctora en ciencias sociales por El Colegio de Michoacán, A. C., actualmente profesora-investigadora de la unidad Golfo del CIESAS. Temas de investigación: estudios regionales, con énfasis en la historia agraria y las relaciones locales de poder. En los tres últimos años ha trabajado también sobre la migración indígena desde el sur de Veracruz hacia la frontera norte del país y las agroindustrias de Sinaloa.

Correo electrónico: emivel@ciesas.edu.mx

Fecha de recepción: 0710 14; Fecha de aceptación: 200315. 
Emilia Velázquez H. Los recorridos de San Pedro y Santiago...

Palabras clave: espacio, territorio, fronteras, prácticas culturales.

Abstract: This article explores how two indigenous groups that live in two different counties of Southern Veracruz and speak different languages constructed a communal territory around the joint use of Soteapan's territory. These groups are Sierra Popoluca speakers and Mecayapan's Nahuas speakers. The article analizes the agrarian reform's impact on the partial dissemination of the Nahua-Popoluca territory by creating new internal borders around the area. On the other hand, this study also shows how cultural practices like the saints visits between Mecayapan and Soteapan have facilitated the symbolic remake of the ancient Nahua-Popoluca territory in spite of the fact the joint use of the lands has disappeared. The central point of the analysis is about the tension and contradiction between local practices of space appropiation and land regulations made by the state goverment. In a nutshell, the article points out the role that some cultural practices, such as the religious ones, play in the development of the nowadays symbolic remake of Popoluca-Nahuat territories.

Keywords: space, territory, borders, cultural recreation.

\section{Introducción}

En investigaciones anteriores he analizado la lógica sociocultural subyacente en la conformación y reproducción del territorio de los zoque-popolucas que habitan en el municipio de Soteapan -al sur del estado Veracruz (México)_ vinculada al uso mancomunado de la tierra entre diferentes poblados popolucas del mismo municipio y poblaciones nahuas pertenecientes a Mecayapan, municipio vecino. Este uso mancomunado de las tierras permitía a los campesinos de ambas entidades movilizarse en diversos espacios productivos que por su ubicación altitudinal favorecía el acceso a productos de distinta índole: agrícolas, de recolección, de caza y pesca. Este elemento de la territorialidad popoluca fue profundamente modificado con la 
Emilia Velázquez H. Los recorridos de San Pedro y Santiago...

aplicación de la reforma agraria ejecutada a principios de la década de 1960, la cual puso fin al uso mancomunado de la tierra y al libre acceso a terrenos localizados en diferentes puntos de uno u otro municipio, dando lugar a la fragmentación del territorio nahua-popoluca (Velázquez, 2001, 2006).

Sin embargo, las formas de apropiación de la tierra, ya sea que éstas cuestionen y desafíen las reglamentaciones estatales, como ocurrió en Soteapan desde finales del siglo XIX hasta inicios de la década de 1960, o las adopten con cierto éxito, como sucedió en la década de 1880 en el vecino municipio nahua de Pajapan (Velázquez, 2009), no son el único soporte del territorio y la territorialidad. Existen otras varias maneras de marcar y apropiarse de espacios materiales y simbólicos que son centrales en la construcción de territorios y territorialidades, tal como ha demostrado Liffman (2012) en su estudio sobre la territorialidad wixarika. Este autor afirma que la territorialidad debe entenderse "en términos que van más allá de una cuestión de hectáreas o control administrativo" (ídem: 27), por lo que el análisis de la territorialidad elaborada por los diferentes grupos sociales debe considerar el parentesco y las redes rituales, entre otros varios aspectos. ${ }^{2}$

Precisamente, en este artículo me propongo analizar el papel que una red ritual elaborada y mantenida en torno a las visitas de las imágenes de los apóstoles Pedro y Santiago, los santos patronos de Soteapan y Mecayapan, tiene en la reproducción de una territorialidad que expresa una antigua y constante interacción entre pobladores popolucas y nahuas que habitan en estos dos municipios vecinos y que, según Gutiérrez (2011), ha contribuido al fortalecimiento de ambas lenguas.

En el primer apartado de este texto se explica el papel central que en la conformación del territorio nahua-popoluca tuvo el uso mancomunado de las tierras que legalmente pertenecían al pueblo indígena de Soteapan, con el fin de mostrar los desfases y tensiones entre las prácticas locales de apropiación del espacio y las legislaciones

${ }^{2}$ Liffman (2012: 27) señala que si bien la territorialidad puede construirse en contra de los discursos y fronteras del Estado, "se define también mediante lazos verticales con programas federales de administración territorial y cultural. Los lazos verticales se hallan entretejidos con los horizontales, establecidos a través del comercio y las luchas por la tierra y el poder con otros pueblos rurales, incluidos otros huicholes". 
Emilia Velázquez H. Los recorridos de San Pedro y Santiago...

y disposiciones administrativas del Estado. En el segundo apartado refiero el largo proceso que condujo al reparto agrario, el cual comenzó a ejecutarse en 1960; el objetivo de este apartado es mostrar que el territorio y las territorialidades construidas en torno al mismo se evalúan y redefinen no sólo en contraposición a las disposiciones estatales, sino también en función de intereses y demandas intracomunitarias en pugna, así como de presiones ejercidas por grupos de interés que actúan en la escala regional. El tercer y último apartado está destinado a analizar cómo es que la práctica de los "velorios" o "velaciones", basada en la "visita" de los santos a diferentes comunidades, propicia una vigencia simbólica del antiguo territorio nahua-popoluca.

Los dos primeros apartados resumen investigaciones previas que ya han sido publicadas, en tanto que el último lo elaboré a partir de información que fui recabando a lo largo de varios años de trabajo de campo en Soteapan y que, al paso del tiempo, me hizo reparar en cómo la práctica religiosa de las "velaciones" reafirmaba las interacciones entre pueblos popolucas, y entre éstos y el pueblo nahua de Mecayapan, pese a que el uso mancomunado de las tierras entre todos ellos había desaparecido medio siglo atrás.

\section{El territorio como construcción sociocultural}

En las últimas décadas, cada vez con mayor frecuencia, se ha cuestionado el supuesto desde el cual se asumía una correspondencia precisa entre una comunidad o pueblo indígena, una delimitación jurídico-administrativa - municipio, ejido, comunidad agraria—, un territorio y una lengua particular. El caso de los zoque-popolucas de Soteapan y los nahuas de Mecayapan ilustra muy bien cómo es que estos cuatro elementos pertenecientes a la organización sociocultural difícilmente encajan con precisión. Ambos pueblos originarios, que habitan en la Sierra de Santa Marta, al sur del estado de Veracruz, y que administrativamente pertenecen a dos municipios diferentes, desde la colonia y hasta mediados del siglo XX practicaron un uso mancomunado de parte de las tierras que eran propiedad de Soteapan. ¿Cómo se llegó a esta situación?

En su clásico estudio sobre los zoque-popolucas, el antropólogo Báez-Jorge (1973) afirma, con base en la consulta de estudios de 


\section{Emilia Velázquez H. Los recorridos de San Pedro y Santiago...}

glotocronología, que este pueblo indígena debió establecerse en Soteapan hacia el año 500 de la era cristiana. ${ }^{3}$ En tanto que el arribo de la población nahua al sur de Veracruz debió ocurrir hacia el año 800 d.C., o incluso un poco antes, como parte de las migraciones nahuas que tuvieron lugar después de la caída de Teotihuacan y Tula, mismas que llegaron hasta Centroamérica (García de León, 1976). Otros grupos de pobladores nahuas se establecieron en el sur de Veracruz hasta los siglos XVI y XVII, cuando tuvieron que abandonar sus poblados de origen ubicados en el antiguo señorío Ayahualulco, en el actual estado de Tabasco, para evitar los daños causados a sus bienes y personas por parte de los corsarios que asolaban la región (García de León, 2004). ${ }^{4}$

De esta manera, al momento de la conquista española en la Sierra de Santa Marta habitaban los zoque-popolucas de Soteapan y los nahuas de Minzapan; siglos después, de Minzapan saldría un grupo de éstos para fundar el pueblo de Pajapan. Por su parte, los nahuas de Mecayapan llegaron a la Sierra en el siglo XVI, en un contexto de desplazamiento de pueblos completos ocasionado por los constantes ataques de piratas a las poblaciones establecidas en las riberas de ríos y lagunas. García de León (2004) señala que los fundadores de Mecayapan arribaron a la Sierra procedentes del antiguo señorío Ahualulco —en el actual Tabasco- - "desde la tercera década del siglo XVI, cuando empezaron a pulular los corsarios franceses" (ídem: 34).

La historia oral de Mecayapan cuenta que cuando sus antepasados llegaron a la Sierra encontraron que las tierras estaban ya ocupadas "por la gente de Pajapan y Soteapan”, y que estos últimos les permitieron

\footnotetext{
${ }^{3}$ El popoluca que se habla en el sur de Veracruz corresponde a dos lenguas diferentes: zoque-popoluca y mixe-popoluca. La primera de ellas se habla en los municipios de Soteapan y Texistepec, en tanto que el mixe-popoluca en los de Sayula de Alemán y Oluta. Ambas lenguas provienen de un tronco común, el proto-zoque-mixe, que debió hablarse hace aproximadamente 3,000 años, y del cual derivaron las lenguas proto-zoque y proto-mixe que se estima empezaron a hablarse hace 1,200 ańos, aproximadamente. Con el paso del tiempo, la lengua proto-zoque se subdividió en zoque de Oaxaca, zoque del Golfo, y zoque de Chiapas (Gutiérrez, 1996, 2001).

${ }^{4}$ El idioma nahua que se habla en el sur de Veracruz corresponde a dos variantes del "pipil del Golfo" (García de León, 1976). En la Sierra de Santa Marta se hablan ambas variantes, una en el municipio de Mecayapan y la otra en el de Pajapan.
} 


\section{Emilia Velázquez $H . \quad$ Los recorridos de San Pedro y Santiago...}

establecerse en un área vecina a Soteapan que era de su propiedad. ${ }^{5}$ Dos documentos elaborados en diferentes momentos del siglo XIX registran el hecho de que los nahuas de Mecayapan vivían y trabajaban en tierras que eran de Soteapan. Así, en 1831 José María Iglesias reportó en la Estadística del Departamento de Acayucan que Santiago Mecayapa era un pueblo indígena que se ubicaba a dos leguas de Joteapa [Soteapan] y que estaba "situado en el mismo terreno que el anterior", disfrutaban como tierras propias una extensión de seis leguas (Iglesias, 1966: 65).

A finales de ese mismo siglo, en el contexto de la desamortización de tierras, las autoridades de los municipios de Soteapan y Mecayapan enviaron un telegrama fechado el 8 de mayo de 1894 donde solicitaban al gobernador del estado un permiso para designar a un apoderado que los representara en todo lo relacionado con las "cuestiones sobre límites de once sitios y cuatro caballerías de tierras pertenecientes a Soteapan para subdividirlas entre ambos pueblos [...]". ${ }^{6}$ Poco después, el apoderado de ambos ayuntamientos explicaba que: "[Aunque] dichas tierras pertenecen en realidad a Xotéapam (...), los Ayuntamientos de Xotéapam y Mecayapam, pueblos entre los cuales reina buena armonía y de los cuales el segundo fue fundado sobre suelo cedido por el primero, han convenido en hacer juntos los gastos que la distribución [de tierras] demande y en efectuar la repartición entre los naturales de ambas localidades". Diez meses después, en otro documento que el alcalde de Soteapan hizo llegar al gobernador del estado, el ayuntamiento de este pueblo proponía la división de sus terrenos en ocho zonas, entre las que incluía Mecayapan, Tatahuicapan y Texizapan; estos dos últimos lugares eran pequeños asentamientos habitados por nahuas que habían salido de Mecayapan para fundar sus propios poblados en tierras pertenecientes a Soteapan. ${ }^{7}$

Después de un prolongado y costoso proceso de medición y deslinde de tierras, Soteapan no logró dividir sus terrenos comunales en los términos propuestos por su cabildo, ya que en 1902 gran parte de las 98,510 hectáreas que reclamaba como propias se entregaron a las

\footnotetext{
${ }^{5}$ Mecayapan se ubica a escasos tres kilómetros de Soteapan.

${ }^{6}$ AGEV, Secretaría de Gobernación, gobernación y justicia, tierras, caja 434, exp. 8.

${ }^{7}$ AGEV, Secretaría de Gobernación, gobernación y justicia, tierras, caja 434, exp. 8.
} 


\section{Emilia Velázquez H. Los recorridos de San Pedro y Santiago...}

herederas del finado Lic. Manuel Romero Rubio, una de las cuales era esposa del presidente Porfirio Díaz. ${ }^{8}$ Popolucas y nahuas se enteraron tardíamente que en la década de 1880 la casi totalidad de las tierras que conformaban los municipios de Soteapan y Mecayapan habían sido declaradas tierras baldías y adquiridas por el Lic. Romero Rubio (Ramírez, 1971).

No obstante este despojo legal de las tierras que Soteapan reclamaba como propias, los nuevos propietarios de estas tierras nunca hicieron uso de ellas. Quizá esto se debió a que el empresario inglés Wheetman Pearson, que en 1905 compró la propiedad a las herederas de Romero Rubio, estaba concentrado en sus actividades de contratista por parte del gobierno federal y en las inversiones privadas que desarrollaba en la planicie. ${ }^{9}$ Otro motivo para no intentar ocupar sus tierras de Soteapan y Mecayapan pudo haber sido la activa participación de los popolucas de Soteapan en la insurrección armada de 1906 contra el régimen de Porfirio Díaz, en alianza con los miembros de los clubes liberales magonistas que existían en las ciudades de la planicie - Coatzacoalcos, Minatitlán y Acayucan- (Azaola, 1982). Cualesquiera que hayan sido las razones para que Pearson no intentara ocupar dichas tierras, esta circunstancia permitió que durante las siguientes seis décadas los popolucas de Soteapan y los nahuas de Mecayapan siguieran usándolas tal como lo habían venido haciendo hasta el momento en que perdieron su propiedad legal.

Es decir, la población popoluca de Soteapan mantuvo el acceso comunal a la tierra y compartió el uso de sus antiguos terrenos comunales con sus vecinos nahuas de Mecayapan. Esto significaba que todo jefe de familia, fuera popoluca o nahua, podía establecer su parcela en cualquier punto del territorio comunal, con la única limitante de no

\footnotetext{
${ }^{8}$ AGEV, Secretaría de Gobernación, gobernación y justicia, tierras, caja 437. Un relato pormenorizado de la pérdida de las tierras comunales de Soteapan puede consultarse en Velázquez (2006: 151 ss.).

${ }^{9}$ Wheetman Pearson estaba a cargo de dos grandes obras que le había encomendado el presidente Porfirio Díaz: la conclusión de la vía del Ferrocarril de Tehuantepec y la construcción de los puertos de altura en Coatzacoalcos y Salina Cruz. Además, como inversor privado había adquirido numerosos terrenos para la exploración petrolera, estaba construyendo la refinería de petróleo de Minatitlán, y se ocupaba de la creación de la Compañía de Petróleo El Águila (Velázquez, 2006).
} 
Emilia Velázquez H. Los recorridos de San Pedro y Santiago...

ocupar un terreno que con antelación otro campesino hubiera abierto al cultivo. Una vez que algún campesino establecía una parcela de labor, éste la trabajaba de manera individual y su unidad doméstica adquiría derechos sobre dicha parcela por tiempo indefinido, aunque no sobre los árboles frutales que ahí hubiera sembrado alguna otra persona. En este caso, la producción de dichos árboles pertenecía indefinidamente a aquel que los hubiera plantado. Asimismo, cuando algún grupo de familias decidía por diversas razones abandonar sus poblados de origen, podía dirigirse a cualquier punto del antiguo territorio popoluca para establecer un nuevo núcleo de población. Fue al amparo de esta lógica de gestión del territorio que en la primera mitad del siglo XX se fundaron varios poblados al oriente y nororiente de la Sierra, que entonces era una área cubierta en gran medida por selva tropical (Velázquez, 2006).

De esta manera, mediante una práctica particular de ocupación del espacio, basada en acuerdos - y seguramente también en desacuerdos y negociaciones - intra e intercomunitarios, popolucas y nahuas construyeron un territorio que trascendía tanto los límites étnico lingüísticos como las definiciones administrativas — divisiones municipales-y las disposiciones legales — adjudicación de la propiedad de la tierra-. Esto es, el territorio no necesariamente se circunscribe a un espacio geográfico delimitado, ni a la posesión legal del mismo, sino que es primordialmente una construcción sociocultural que difícilmente tiene alguna concordancia precisa con límites geográficos y definiciones legales. Son justamente estas discordancias, o estos desfases —en términos de Viqueira (2000)_, las que debemos analizar para entender tanto las lógicas culturales que subyacen en la conformación de los territorios como las posibilidades de subvertir la normatividad estatal.

\section{El territorio: un espacio de interacciones múltiples}

Como toda construcción social, los territorios son validados mediante acciones individuales y grupales basadas en concepciones que las personas van creando en relación con los espacios por los que se movilizan. A la vez, los territorios y sus territorialidades - reglas, acuerdos, acciones - son repensados y reconsiderados a partir de los intereses y necesidades internas que en distintos momentos históricos 
Emilia Velázquez H. Los recorridos de San Pedro y Santiago...

desarrollan los diferentes grupos que han construido determinada idea de territorio, la cual está ligada siempre a un proyecto particular de comunidad que puede ser asumido explícita o implícitamente, es decir, reivindicándolo de manera consciente o viviéndolo como algo dado y vivido sin mayores cuestionamientos. Pero los territorios y las territorialidades que en torno a ellos se elaboran también son repensados y reconsiderados en diálogo o confrontación con proyectos estatales objetivados en leyes, normatividades jurídicas, programas gubernamentales, etcétera.

Desde esta perspectiva, y como hemos visto en el apartado anterior, en las dos últimas décadas del siglo XIX la territorialidad nahua-popoluca debió ser repensada a la luz de las leyes agrarias liberales, optándose por conservar un viejo acuerdo de compartir las tierras de Soteapan con los campesinos nahuas de Mecayapan, a la vez que unos y otros buscaron adaptarse a las disposiciones estatales de subdividir los terrenos comunales de Soteapan en grandes lotes de condueńazgo (Velázquez, 2009). Al no lograr este objetivo, en 1906 exploraron una vez más la vía de la confrontación violenta con el gobierno, ${ }^{10}$ que si bien no les permitió recuperar la posesión legal de sus antiguos terrenos comunales sí coadyuvó a que en el imaginario regional la Sierra fuera considerada un espacio peligroso, tanto por el desconocimiento que se tenía de lo que aparecía básicamente como un monte cerrado, como por la ferocidad que en varias ocasiones habían demostrado los popolucas de Soteapan en sus protestas contra las disposiciones gubernamentales. A esta circunstancia se sumó el desorden "revolucionario" ocasionado por las luchas entre distintas facciones político-militares que en la planicie se enfrentaron durante la década 1910-1920 (Delgado, 2006, 2009). Ambas condiciones permitieron a popolucas y nahuas replegarse en su antiguo territorio y mantener el uso mancomunado de las tierras y el acceso comunal a las mismas durante los siguientes veinticinco ańos, hasta que en 1931 las autoridades municipales de Soteapan decidieron recurrir a la nueva ley agraria para recuperar sus antiguas tierras comunales.

10 En los informes de gobernadores compilados por Blázquez (1986) hay varias referencias a pequeńas insurrecciones escenificadas por la población zoque-popoluca de Soteapan, habiendo sido la más notable la que se perpetró en 1888 (Velázquez, 2006). 
Emilia Velázquez H. Los recorridos de San Pedro y Santiago...

A partir de esta fecha, y hasta 1960, popolucas de Soteapan y nahuas de Mecayapan, en interlocución con la ley agraria del Estado mexicano posrevolucionario, debatieron su concepto de territorio. Para un grupo numeroso de popolucas, liderado por "hombres fuertes" de la comunidad, era fundamental obtener la restitución de sus antiguas tierras comunales para seguirlas usando en forma mancomunada. La legitimidad de estos líderes descansaba en su participación en el levantamiento de 1906, así como en su conocimiento de los "misterios" del carnaval que cada año debían llevar a cabo las autoridades municipales de Soteapan para garantizar las buenas cosechas de maíz e impedir la entrada de enfermedades al pueblo. ${ }^{11}$

En tanto que otro grupo, tanto de popolucas como de nahuas de Mecayapan y Tatahuicapan, estaba de acuerdo con la dotación de ejidos para cada uno de los poblados de ambos municipios, tal como lo proponía el Departamento Agrario y la Liga de Comunidades Agrarias y Sindicatos Campesinos de Veracruz. Los líderes de este grupo tenían estrecha relación con los dirigentes de la Liga, y más tarde con el Comité Regional Campesino de la Central Nacional Campesina (CNC), lo que les otorgaba una posición política relevante en sus comunidades.

Durante casi treinta años, agraristas y comunalistas lucharon por obtener unos la dotación ejidal, y otros la restitución de tierras comunales. En esta pugna intracomunitaria, el grupo defensor del proyecto comunalista mostró su fuerza política al lograr detener el reparto agrario por casi treinta ańos, tiempo durante el cual se mantuvo la posesión mancomunada de las tierras entre Soteapan y Mecayapan y el acceso comunal a la tierra, con el agravante de que legalmente las tierras no les pertenecían y habían pasado a ser tierras nacionales.

Hacia mediados de la década de 1950, esta situación fue aprovechada por grupos de ganaderos mestizos del centro del estado de Veracruz y de Acayucan, quienes amparándose en el proyecto estatal de colonización del trópico, iniciado en la década de 1940, empezaron a solicitar al gobierno federal la dotación de Colonias Agrícolas Ganaderas, una figura jurídica mediante la cual se otorgaban tierras en propiedad privada en

\footnotetext{
${ }^{11}$ Una descripción detallada de este ritual colectivo puede consultarse en Velázquez (2006, capítulo 6).
} 


\section{Emilia Velázquez H. Los recorridos de San Pedro y Santiago...}

áreas deshabitadas que eran susceptibles de colonizar. La dotación de una colonia de este tipo — La Perla del Golfo_ - en la parte norte de la Sierra, cubierta entonces casi completamente de selva tropical, obligó a que los comunalistas renunciaran a su pretensión de recuperar sus tierras mediante la restitución y a aceptar la dotación de ejidos individuales a cada uno de los poblados de los municipios de Soteapan y Mecayapan. ${ }^{12}$

Esta reforma agraria tardía - en comparación con lo sucedido en otras regiones del país en donde las primeras dotaciones de tierras ejidales ocurrieron en la segunda década del siglo XX- dio por terminado el acceso mancomunado a las antiguas tierras comunales de Soteapan. De esta manera, el antiguo territorio popoluca empezó a fragmentarse, tendencia que se acentuó en las siguientes dos décadas a causa del desarrollo de un proceso de colonización de la selva para crear nuevos ejidos y una colonia más — La Magdalena- Con ello, los campesinos popolucas y nahuas perdieron la posibilidad de transitar libremente por los diferentes espacios del antiguo territorio nahua-popoluca, ya que la reforma agraria trajo consigo la creación de fronteras y linderos hasta entonces desconocidos. A cada poblado se le adjudicó un ejido con una superficie claramente delimitada, a la que ya no podrían acceder los campesinos de otros poblados, aun cuando éstos tuvieran ahí milpas y a veces cafetales. Es decir, con la reforma agraria los campesinos popolucas y nahuas perdieron el control que hasta entonces habían tenido sobre amplias extensiones de terreno, éstas iban desde $200 \mathrm{msnm}$ en la parte sur de la Sierra, a donde numerosas familias campesinas de Soteapan y San Fernando se trasladaban por temporadas para sembrar maíz; hasta el nivel del mar al nororiente de la Sierra, a donde eventualmente acudían a pescar. Otro espacio sobre el que tenían dominio era el de las partes altas del volcán Santa Marta —más de 1,200 msnm—, en donde podían cazar "animales de monte" y colectar frutos comestibles y bejucos para hacer sus canastos. ${ }^{13}$

Un primer aspecto que me interesa destacar de esta historia refiere a la necesidad de reconocer las diferencias entre espacio geográfico, espacialidad y territorio. Así, en cualquier espacio geográfico

\footnotetext{
${ }^{12}$ Un análisis detallado de este proceso puede consultarse en Velázquez (2006).

${ }^{13}$ Sobre el uso de estos distintos espacios puede consultarse Velázquez (2001).
} 


\section{Emilia Velázquez H. Los recorridos de San Pedro y Santiago...}

coexisten diferentes espacialidades, es decir, distintas construcciones sociales mediante las cuales se percibe el espacio (Hoffmann, 2001). En el caso aquí narrado, el espacio geográfico reclamado como parte del territorio popoluca se veía por los peritos del Departamento Agrario en términos de número de hectáreas, calidad de la tierra y disposiciones legales: era una espacialidad ligada a la construcción de un Estado posrevolucionario en cuya conformación era central la reforma agraria. Pero ese mismo espacio geográfico se concebía por la población popoluca y nahua como un espacio de reproducción material y simbólica del grupo; es decir, como un territorio con numerosos significados y atribuciones culturales.

Este territorio se conformaba por cuatro diferentes espacios visibles: por un lado, y en estrecha relación, se encontraban los espacios agrícola y de habitación, dominados básicamente por los hombres y mujeres a partir del trabajo cotidiano en milpas y solares. Sobre estos espacios ejercían un dominio particular ciertos seres sobrenaturales: por un lado estaba Homshuk, el dios del maíz, al que se veneraba mediante rituales practicados tanto en la casa como en la milpa; por otra parte, el Chaneco era invocado durante la realización de rituales mágico-religiosos y de sanación que se realizaban en ojos de agua, cascadas, ríos, y se ubicaban en las inmediaciones de los poblados. Un tercer espacio era el de "la montaña", que es como localmente se le denomina a la selva tropical existente en el volcán Santa Marta; espacio dominado por chanecos y otros seres sobrenaturales ${ }^{14}$ a quienes los hombres debían honrar para ser admitidos sin ser castigados; un cuarto espacio era el de los ríos y el mar, donde iban a pescar.

Tal territorio no se circunscribía a los límites municipales, como sí parece ser el caso de otros varios territorios indígenas que existen en otras partes del país (Rodríguez, 2000), sino que sus límites imaginados iban mucho más allá de los municipios de Soteapan y Mecayapan, ${ }^{15}$

14 Descripciones de estos seres naturales recabadas en distintas épocas pueden consultarse en Williams (1961), Foster (1966), Leonti (2002).

15 "Las tierras de Soteapan llegaban hasta Acayucan y Catemaco, el lindero pasaba en medio de la laguna [de Catemaco], por ahí pasaba, según me contó un señor que ahora ya está muerto y era de Buenavista" (entrevista con M. H., ejidatario de 70 años, Soteapan, 08/02/00). "Las tierras de Soteapan llegaban hasta Corral Nuevo, Acayucan 


\section{Emilia Velázquez H. Los recorridos de San Pedro y Santiago...}

además de trascender la superficie terrestre, como lo ejemplifican varias narraciones acerca de un cerro - Tambor- que se eleva entre los municipios de Soteapan y Mecayapan. Según una de esas narraciones, al interior de dicho cerro existen enormes casas en las que se encuentran los textos que contienen los misterios de la sabiduría de los hombres rayo, la cual sólo unos pocos sabían interpretar y manejar en el pasado. ${ }^{16}$ En otra narración que registré, el cerro Tambor aparece como escenario de cruentas luchas entre los sabios popolucas, hombres rayo de San Pedro Soteapan y otras localidades - Ocozotepec, Buenavista-, por un lado, y los sabios de otros lugares, particularmente de Oaxaca, que trataron de destruir Soteapan haciendo explotar el cerro. ${ }^{17}$

Un segundo aspecto a destacar es que el territorio tiene cuando menos cuatro dimensiones importantes que frecuentemente están desfasadas entre sí; estas dimensiones son: la geográfica, la legal, la político-administrativa, y la cultural. En el caso que aquí he narrado, las dimensiones geográfica y político-administrativa no se han correspondido mecánicamente con el territorio popoluca, concebido y recreado a partir de la dimensión cultural. De igual manera, durante sesenta ańos el constante dominio ejercido mediante la apropiación física y simbólica de dicho territorio ocurrió en abierto desfase con la dimensión legal. El espacio geográfico - las tierras de los municipios de Soteapan y Mecayapan - fueron propiedad legal de la familia Romero Rubio, de Weetman Pearson, de Pemex y de la nación; pero el dominio real de estas tierras, en tanto parte del territorio popoluca-nahua, lo ejercieron los campesinos de Soteapan y Mecayapan bajo la conducción de un grupo de ancianos sabios — aquellos que tenían "dones" — de San Pedro Soteapan.

y Jáltipan, yo me acuerdo que de nińa vi una mojonera, en donde comienza Jáltipan, que decía San Pedro Soteapan” (entrevista con C. P. Pérez $(\dagger)$, aproximadamente 85 años, hija de un ex revolucionario, San Pedro Soteapan, 21/05/99).

16 "Hay muchas casas grandes por allá abajo, adentro [del cerro Tambor]. Dicen que hay muchas cartas brillantes ahí en esas casas, pero si vas a tocar y no sabes nada, esa carta te va a llevar quién sabe hasta dónde. Y el que ya sabe, lo agarra y se lo lleva [la carta], pues ése ya lo sabe manejar, ya ha aprendido cosas" (entrevista con B. H., profesora popoluca, 45 años, San Pedro Soteapan, 07/02/00).

${ }^{17}$ Entrevistas con H. M., esposa de ejidatario, 45 años aproximadamente (San Pedro Soteapan, 14/02/07) y N. G., 90 años (San Pedro Soteapan, 02/11/99). 


\section{Vigencia simbólica del territorio nahua-popoluca: los recorridos de San Pedro y Santiago Apóstol}

Una vez consumado el reparto agrario, al interior de los ejidos se mantuvo el acceso comunal a la tierra, conformándose así lo que localmente fueron denominados "ejidos comunales", una categoría legalmente inexistente pero localmente válida y legítima. Lo que caracterizaba a estos "ejidos comunales" era que no obstante que las tierras ejidales habían sido adjudicadas a un número determinado de beneficiarios, todo campesino de la localidad podía hacer un uso individual por tiempo indefinido de alguna porción de dichas tierras. Es decir, se aceptaron los ejidos individuales —uno por pobladopero, al mismo tiempo, al interior de cada ejido se resignificó el concepto estatal para adecuarlo a la lógica cultural propia del acceso comunitario a las tierras, que era uno de los ejes estructuradores del territorio popoluca. ${ }^{18}$

Sin embargo, debido a que el reparto agrario se ejecutó casi treinta años después de haberse iniciado los trámites para dotación de ejidos, y más tarde de restitución de tierras comunales, ${ }^{19}$ los terrenos para uso agrícola de los ejidos dotados entre 1960 y 1963 estaban prácticamente todos ocupados, lo que obligó a familias jóvenes a crear nuevos poblados al sur y oriente de la Sierra para después solicitar la dotación de tierras ejidales. Quienes migraron hacia las tierras bajas al sur de la Sierra ocuparon tierras fértiles que ya venían usando campesinos de San Pedro Soteapan y San Fernando para sembrar maíz.

${ }^{18}$ En la década de 1970 varios de estos ejidos se parcelaron, en tanto que otros más, incluido el ejido Soteapan, empezaron a hacerlo hasta mediados de la década de 1990, al amparo del Programa de Certificación de Derechos Ejidales y Titulación de Solares Urbanos (Procede), encargado de ejecutar los cambios al artículo 27 constitucional aprobados por el poder legislativo en 1992 (Velázquez, 1999).

${ }^{19}$ En 1931 un grupo de ex revolucionarios popolucas envió una solicitud de dotación de tierras ejidales. Sin embargo, al percatarse de que no era posible obtener un solo ejido que incluyera a todos los poblados popolucas y nahuas que hacían uso de las antiguas tierras comunales de Soteapan, en 1936 optaron por solicitar restitución de tierras comunales. En los siguientes años, ambos expedientes se mantuvieron abiertos y fueron utilizados, uno por los "agraristas", y otro por los "comunalistas" (ACAM, exps. 1432 y 2737). 


\section{Emilia Velázquez H. Los recorridos de San Pedro y Santiago...}

En cambio, aquellos que se fueron a poblar la parte oriental de la Sierra enfrentaron una situación más difícil, pues la mayoría de los terrenos que iban ocupando estaban cubiertos de selva, por lo que debieron talarla para sembrar, descubriendo muy pronto que dichas tierras perdían rápidamente su fertilidad. ${ }^{20}$

Con el reparto agrario se perdió, o se limitó severamente, la posibilidad de transitar libremente por los distintos espacios del antiguo territorio comunal. Ahora cada grupo de ejidatarios y "comuneros", término utilizado para denominar a quienes no tenían un derecho agrario pero ocupaban tierras del ejido para hacer sus milpas, debía circunscribirse a las fronteras ejidales delimitadas por los peritos del Departamento de Asuntos Agrarios y Colonización (DAAC). Pero quienes sí pudieron seguir transitando libremente entre los nuevos ejidos fueron los santos patronos de Soteapan y Mecayapan: los apóstoles Pedro y Santiago, acompańados por sus mayordomos y diputados. Sin embargo, el caminar de estos santos quedó circunscrito a la vieja área de poblamiento zoque-popoluca y nahua, particularmente al occidente y suroccidente de la Sierra, ya que acudir a los nuevos ejidos que empezaron a crearse al oriente de la Sierra resultaba sumamente difícil por las distancias que había que recorrer. Además, los pobladores - popolucas, nahuas y mestizos - de estos nuevos ejidos consumían gran parte de sus energías en dominar la selva para construir sus poblados, abrir tierras al cultivo y construir caminos y veredas que los comunicaran, ya no con San Pedro Soteapan o Mecayapan sino con Tatahuicapan, el poblado (nahua) de más fácil acceso que tenía comunicación por carretera con Minatitlán, ${ }^{21}$ lo que facilitaba la llegada de compradores y vendedores de granos básicos y otros productos alimenticios y de trabajo.

\footnotetext{
${ }^{20}$ Sobre el proceso de colonización ejidal de la parte oriental de la Sierra ver el trabajo de Durand (2000).

${ }^{21}$ Bradley (1988) ha analizado las particularidades de este proceso de colonización y formación de lo que él ha denominado micro región oriente de la Sierra, subrayando los cambios ocurridos en la identidad de la población popoluca a partir de sus interacciones con un nuevo entorno natural, pues pasaron de vivir en la ladera occidental del volcán Santa Marta a la planicie costera que colinda con el Golfo de México. En este proceso de adaptación fueron acompańados tanto por antiguos vecinos popolucas y nahuas que se trasladaron al oriente de la Sierra para obtener tierras ejidales, como por ejidatarios mestizos procedentes de otras partes del estado de Veracruz.
} 
Emilia Velázquez H. Los recorridos de San Pedro y Santiago...

En este contexto, el occidente y suroccidente del municipio de Soteapan devino en un ámbito de "persistencia étnica" a partir de la recreación de una territorialidad popoluca asociada a "prácticas culturales específicas que alimentan y se alimentan de las diferencias étnicas, es decir, de las 'identidades' ” (Hoffmann, 2001: 287). Una práctica cultural fundamental ha sido el tránsito constante de San Pedro, el santo patrono de los popolucas, por las diferentes localidades del occidente y suroccidente del municipio de Soteapan. Este desplazamiento de San Pedro se asocia a los "velorios" o "veladas" que tienen lugar cuando una familia de algún poblado solicita la imagen de San Pedro para, "según la promesa que se haya hecho", tenerla durante una o dos noches en su casa. Los velorios se realizan para pedir algún favor al santo, como obtener buenas cosechas o tener éxito en la cría de ganado, para conseguir trabajo o recuperar la salud:

Aquí la tradición es que se hace una promesa para pedir al señor ayuda para el trabajo, para el campo o ganado. Si compro ganado, o antes [de la compra], se hace velorio para pedirle ayuda al santo, igual del pollo y del cochino. ${ }^{22}$

Dicha celebración también se lleva a cabo para dar gracias por algún favor solicitado al santo y que éste ha concedido. En la realización de estos velorios participan vecinos y amigos, quienes aportan trabajo, leńa, café, azúcar, maíz y otros productos necesarios para hacer la comida con la que se acompaña el ritual, el cual consiste en velar al santo y rezarle, entre otras muchas y elaboradas acciones que acompañan el ceremonial, antes y durante el velorio, entre las que destacan la estricta abstinencia sexual, la elaboración de comida ritual, la vigilia obligada de quienes organizan el velorio, y la realización en la madrugada de baños rituales de purificación en algún río o salto de agua particular. ${ }^{23}$ En algunos velorios no sólo se solicita a San Pedro sino también a Santiago, el santo patrono de Mecayapan, quien es muy valorado como

\footnotetext{
${ }^{22}$ Entrevista con M.H., ejidatario y rezandero, San Pedro Soteapan, 09/09/07.

${ }^{23}$ Entrevistas con M.H, San Pedro Soteapan,, 09/09/07; S.G., Amamaloya, 15/(05/97; S.D, San Pedro Soteapan, (13/04/08).
} 
Emilia Velázquez H. Los recorridos de San Pedro y Santiago...

dador de éxitos vinculados con la ganadería. Una de las personas con la que platiqué sobre esta visitas de los santos afirmaba que es frecuente que a San Pedro se le organice un velorio para darle gracias - o para pedirle favores - en relación con la buena marcha de la agricultura y la cría de las aves de corral, mientras que a Santiago se le pide por el bienestar del ganado — reses, marranos, caballos_. ${ }^{24}$ Así lo expresaba un señor de San Pedro Soteapan:

A Santiago tú pides para comprar tu ganadito, él te apoya, él te ayuda. Entonces cuando ya progresó tu corralito entonces aquel señor va y él dice: "apóstol, te vine a pedir para ir a velar a mi casa porque tu obra ya está". Igual a San Pedro, si le pediste por tu siembra, tu cosecha, entonces cuando ya esa cosecha progresó, dio buen resultado, entonces el que pidió tiene que ir a decir: "[San Pedro] ya está el resultado, te llevo a mi casa de voluntad a hacer la velación”. ${ }^{25}$

En 1999, un anciano popoluca de más de 90 años me contaba que siempre estaba la costumbre de que el santo de Mecayapan visitara a los popolucas:

[Anteriormente] el santo se pasaba hasta tres meses por acá (...), [lo llevaban] a Ocotal Grande, Ocotal Chico, San Fernando, Ocozotepec, Tulín, Buenavista, Tierra Nueva, Sabaneta, Los Mangos, Horno de Cal, Cuilonia y Amamaloya. ${ }^{26}$

En 1967, la etnóloga Waltraud Hangert presenció una de estas visitas del santo de Mecayapan y lo registró en los siguientes términos:

[...] la imagen de Santiago de Mecayapan, cabecera municipal vecina a Soteapan, fue llevada a Soteapan. Los hombres que la cargaban tenían que caminar con ella más de una hora y pasar

\footnotetext{
${ }^{24}$ Entrevista con S.G., profesionista popoluca, Amamaloya, 15/05/97.

${ }^{25}$ Entrevista con M.H., rezandero de 70 años, San Pedro Soteapan, 20/08/00.

${ }^{26}$ Entrevista con M.S. (†), ejidatario, San Pedro Soteapan, 01/12/99.
} 


\section{Emilia Velázquez H. Los recorridos de San Pedro y Santiago...}

tres ríos en el camino. Antes de la llegada de la procesión, algunos ancianos y el sacristán hicieron en el patio de la iglesia de Soteapan un nicho para San Pedro, santo patrón de este lugar. Después recibieron a la imagen de Santiago y la llevaron dentro de la iglesia. Posteriormente salieron con los dos santos, acompañados por cantores, tamboreros, flautistas y gente del pueblo y se dirigieron a algunas congregaciones cercanas para hacer una colecta o - como dijo el sacristán— para llevarlos a pasear (Hangert, 1992: 78).

En 2008 la imagen de "Santiaguito" seguía siendo solicitada en diversos pueblos popolucas, aunque al parecer ya no pasaba por la iglesia de Soteapan. Según el encargado de la parroquia de Mecayapan, quien en una libreta anota todas las peticiones para llevar al santo de visita a diversos pueblos, los poblados popolucas a los que acuden son Morelos, Aguacate, Loma de Sogotegoyo, ${ }^{27}$ Tulín, Buenavista, San Pedro Soteapan, El Cañal, Ocozotepec, Benito Juárez, Amamaloya, Ocotal Chico y Ocotal Grande. En algunos de estos lugares, como Aguacate y Buenavista, Santiago es solicitado hasta dos o tres ocasiones por año. ${ }^{28}$ Ésta es la misma ruta que recorre la imagen de San Pedro. ${ }^{29}$ En dichas visitas, encabezadas por el mayordomo, el santo recibe ofrendas que aquél utilizará para hacerle su fiesta anual, o para gastos que se requieran en la iglesia:

Pantaleón fue el mayordomo de San Pedro en este año. Se colecta en las comunidades que solicitan la imagen. A veces, en alguno de los velorios se junta con Santiago, después se separan y cada quien sigue su compromiso. Todos los asistentes dan limosnas que el mayordomo recoge. ${ }^{30}$

\footnotetext{
${ }^{27}$ Aguacate y Loma de Sogotegoyo pertenecieron hasta la década de 1930 al municipio de Soteapan y después "por motivos políticos" pasaron a formar parte del municipio de Hueyapan de Ocampo.

${ }^{28}$ Entrevista con T.H., encargado de la parroquia de Mecayapan, 08/02/08.

${ }^{29}$ Entrevista con M.H., esposa presidente parroquial, San Pedro Soteapan, 29/05/97.

${ }^{30}$ Entrevista con M.H., ejidatario y rezandero, San Pedro Soteapan, 09/09/07.
} 
Emilia Velázquez H. Los recorridos de San Pedro y Santiago...

De esta manera, el tránsito de los santos actualiza constantemente la coherencia simbólica de un espacio que a finales del siglo XIX constituía el área habitada de Soteapan-Mecayapan, aquella donde se realizaban una serie de prácticas y rituales — carnaval, fiestas a los santos, curaciones- que expresaban las prácticas culturales distintivas de los grupos zoque-popoluca y nahua. Así, en Soteapan la práctica de los velorios permite reafirmar la membresía a la comunidad popoluca y la estrecha relación que por siglos se ha mantenido con los nahuas de Mecayapan:

Aquí nosotros [en Soteapan] sí lo reconocemos a Santiago (...), lo traen las mujeres encargadas de su cuidado, a veces vienen tres señores también con el santo (...) Nunca hemos tenido problemas con los de Mecayapan, nos respetan y los respetamos; son nuestros vecinos, no discutimos nada, nos invitan a su fiesta de Santiago. Y cuando aquí había carnaval [los de Mecayapan] venían a fiestar. ${ }^{31}$

\section{Reflexiones finales}

La historia aquí narrada muestra que si bien el territorio supone generalmente un espacio geográfico, uno y otro no se corresponden mecánicamente. El espacio geográfico deviene en territorio a partir de que un determinado sujeto social crea y ejerce un conjunto de vínculos de dominio, de poder, de pertenencia o de apropiación sobre una porción o la totalidad de cierto espacio geográfico (Montañez, 2001). Por otro lado, este territorio puede tener "vigencia simbólica" (Uzeta, 2004: 132) aun cuando el espacio geográfico con el que se ha relacionado haya sido alterado mediante, por ejemplo, la creación de fronteras internas o la modificación dramática del paisaje, que pueden resultar de la conflictiva relación de poder entre actores sociales con distintos proyectos económicos y políticos.

Por otra parte, el territorio está definido y recreado en gran parte por lazos subjetivos de identidad y afecto que se expresan mediante prácticas culturales que manifiestan valores y jerarquías con los que se identifican

\footnotetext{
${ }^{31}$ Ibídem.
} 
Emilia Velázquez H. Los recorridos de San Pedro y Santiago... grupos sociales particulares más allá de sus diferencias internas. En este artículo he expuesto una de esas prácticas — los desplazamientos de los santos para la realización de los velorios - mediante la cual se recrea una determinada territorialidad que en el pasado tuvo uno de sus anclajes en el uso mancomunado de las tierras entre popolucas y nahuas. Otro de esos anclajes ha sido el recorrido de San Pedro y Santiago Apóstol por los diferentes pueblos popolucas con los que en el pasado los nahuas compartieron tierras. El primero desapareció, el segundo continúa hasta la actualidad, aunque en el futuro esta práctica puede debilitarse a causa de la expansión de diferentes denominaciones de la religión protestante. Hasta ahora, la gran mayoría de los pueblos popolucas sigue siendo principalmente católica, no así Mecayapan y otros pueblos nahuas, en donde los católicos representan una verdadera minoría. De esta manera, si en el pasado remoto los nahuas de Mecayapan dependieron de los popolucas para tener un lugar donde vivir y trabajar, actualmente la minoría católica de Mecayapan depende en parte de los pueblos popolucas para mantener y recrear el culto a Santiago Apóstol, un santo cuya fama de ayudar a quienes se dedican a la ganadería ha hecho que su agenda de visitas esté saturada y éstas se extiendan hacia poblaciones mestizas ubicadas en la planicie, tales como Acayucan y San Juan Evangelista.

\section{Siglas}

AGEV Archivo General del Estado de Veracruz.

ACAM Archivo de la Comisión Agraria Mixta.

DAAC Departamento de Asuntos Agrarios y Colonización.

\section{Bibliografía citada}

Azaola Elena, 1982, Rebelión y derrota del magonismo agrario, SEPFCE, Colección SepOchentas, México.

Báez-Jorge, Félix, 1973, Los Zoque-Popolucas. Estructura social, INI, Colección SEP/INI, núm. 18, México. 
Blázquez, Carmen (compiladora), 1986, Estado de Veracruz. Informes de sus gobernadores (1826-1986), Editora del Gobierno de Veracruz, Tomo V, Jalapa, Veracruz.

Bradley, Richard, 1988, Processes of sociocultural Change and ethnicity in Southern Veracruz, Mexico, Ph. D. Thesis Dissertation, University of Oklahoma.

Delgado, Alfredo, 2006, Acayucan. Cuna de la Revolución, Tomo 1, Grupo Editorial Publicom, Acayucan, Veracruz.

Delgado, Alfredo, 2009, "Espacios y luchas revolucionarias en el Sotavento veracruzano", en E. Velázquez, E. Léonard, O. Hoffmann y M.-F. Prévôt-Schapira (coordinadores), El Istmo mexicano: una región inasequible. Estado, poderes locales $y$ dinámicas espaciales (siglos XVI-XXI), CIESAS-IRD, México, pp. 353-392.

Durand, Marcia Leticia, 2000, La colonización en la Sierra de Santa Marta: perspectivas ambientales y deforestación en una región de Veracruz, Tesis de doctorado, Instituto de Investigaciones Antropológicas UNAM, México.

Foster, George, 1966 [1942], A Primitive Mexican Economy, University of Washington Press, Seattle.

García de León, Antonio, 1976, Pajapan, un dialecto mexicano del Golfo, INAH, Colección Científica núm. 43, México.

García de León, Antonio, 2004, Contra viento y marea. Los piratas en el Golfo de México, Plaza y Janés, México.

Gutiérrez Morales, Salomé, 1996, Duración vocálica en protozoque del Golfo, CIESAS, INI México.

Gutiérrez Morales, Salomé, 2001, "El popoluca, ¿¿una lengua zoque?”, en Transición, núm. 38, pp. 66-69.

Gutiérrez Morales, Salomé, 2011, Dinámicas lingüisticas entre los popolucas y nahuas del sur de Veracruz, Consejo Veracruzano de Investigación Científica y Desarrollo Tecnológico, México.

Hangert, Waltraud, 1992 [1976], "La mayordomía entre los popolucas de Soteapan", en W. Hangert, Religión y vida cotidiana, Dirección General de Culturas Populares-Unidad Regional 
Emilia Velázquez H. Los recorridos de San Pedro y Santiago...

Sur de Veracruz, CNCA, Casa de Cultura de Minatitlán, Ver., Acayucan, Veracruz.

Hoffmann, Odile, 2001, "Del territorio étnico a la ciudad: las expresiones de identidad negra en Colombia a principios del siglo XXI", en Grupo de Investigación Territorialidades, Territorio y Cultura, Territorios en conflicto y cambio sociocultural, Universidad de Caldas, Colombia, pp. 277-307.

Iglesias, José María, 1966 [1831], Acayucan en 1831, Editorial Citlaltépetl, Colección Suma Veracruzana, Serie Antropología, Jalapa, Veracruz.

Liffman, Paul, 2012, La territorialidad wixarika y el espacio nacional. Reivindicación indígena en el occidente de México, El Colegio de Michoacán, CIESAS, México.

Leonti, Marco, 2002, Moko/ La Rosa Negra, Ethnobotany of Teh Popoluca, Veracruz, México, Thesis for the degree of Doctor of Natural Sciencies, Swiss Federal Institute of Technology, Zurich.

Montañez Gómez, Gustavo, 2001, “Introducción. Razón y pasión del espacio y el territorio", en Red Espacio y Territorio, Espacio y territorios. Razón, pasión e imaginarios, Universidad Nacional de Colombia, Bogotá, Colombia, pp. 15-32.

Ramírez Lavoignet, David, 1971, “Soteapan: luchas agrarias”, Universidad Veracruzana (Seminario de Historia), Jalapa, Veracruz (inédito).

Rodríguez, María Teresa, 2000, "Ritual, identidad y transformaciones locales en un espacio interétnico", en The Journal of Intercultural Studies, núm. 27, pp. 172-183.

Uzeta, Jorge, 2004, El camino de los santos. Historia y lógica cultural otomí en la Sierra Gorda guanajuatense, El Colegio de Michoacán, Ediciones La Rana, México.

Velázquez, Emilia, 1999, "El parcelamiento de tierras ejidales en una subregión cafetalera del sur de Veracruz", Estudios Agrarios, núm. 12, pp. 175-195.

Velázquez, Emilia, 2001, "El territorio de los popolucas de Soteapan, Veracruz: transformaciones en la organización y apropiación del espacio", Relaciones, vol. XXII, núm. 87, pp. 17-47. 
Emilia Velázquez H. Los recorridos de San Pedro y Santiago...

Velázquez, Emilia, 2006, Territorios fragmentados. Estado y comunidad indígena en el Istmo veracruzano, CIESAS, El Colegio de Michoacán, México.

Velázquez, Emilia, 2009, "Las comunidades indígenas del Istmo veracruzano frente al proyecto liberal de finales del siglo XIX", en E. Velázquez, E. Léonard, O. Hoffmann y M.-F. PrévôtSchapira (coordinadores.), El Istmo mexicano: una región inasequible. Estado, poderes locales y dinámicas espaciales (siglos XVI-XXI), CIESAS-IRD, México, pp. 291-352.

Viqueira, Juan Pedro, 2000, "Una historia en construcción: teoría y práctica de los desfases”, en M. J. Hernández Madrid y J. Lameiras Olvera (editores.), Las ciencias sociales y humanas en México: sintesis y perspectivas de fin de siglo, El Colegio de Michoacán, Zamora, Michoacán, pp. 119-159.

Williams, Roberto, 1961, "Los popolucas del sur de Veracruz", INAHCAPFCE-SEP (Consejo de Planeación e Instalación del Museo Nacional de Antropología), México (mecanoescrito inédito). 